\title{
Aquaporin Expression in Normal and Pathological Skeletal Muscles: A Brief Review with Focus on AQP4
}

\author{
Yoshihiro Wakayama \\ Department of Neurology, Showa University Fujigaoka Hospital, 1-30 Fujigaoka, Aoba-ku, Yokohama, 227-8501, Japan \\ Correspondence should be addressed to Yoshihiro Wakayama, wakayama@showa-university-fujigaoka.gr.jp \\ Received 18 September 2009; Revised 12 January 2010; Accepted 17 January 2010 \\ Academic Editor: Aikaterini Kontrogianni-Konstantopoulos
}

Copyright ( $\odot 2010$ Yoshihiro Wakayama. This is an open access article distributed under the Creative Commons Attribution License, which permits unrestricted use, distribution, and reproduction in any medium, provided the original work is properly cited.

\begin{abstract}
Freeze-fracture electron microscopy enabled us to observe the molecular architecture of the biological membranes. We were studying the myofiber plasma membranes of health and disease by using this technique and were interested in the special assembly called orthogonal arrays (OAs). OAs were present in normal myofiber plasma membranes and were especially numerous in fast twitch type 2 myofibers; while OAs were lost from sarcolemmal plasma membranes of severely affected muscles with dystrophinopathy and dysferlinopathy but not with caveolinopathy. In the mid nineties of the last century, the OAs turned out to be a water channel named aquaporin 4 (AQP4). Since this discovery, several groups of investigators have been studying AQP4 expression in diseased muscles. This review summarizes the papers which describe the expression of OAs, AQP4, and other AQPs at the sarcolemma of healthy and diseased muscle and discusses the possible role of AQPs, especially that of AQP4, in normal and pathological skeletal muscles.
\end{abstract}

\section{Introduction}

Water is an essential substance for mammals, invertebrates, plants, and microorganisms. Water channel proteins named aquaporins (AQPs) have been found in the cell membranes of these organisms. In mammals, they have been identified in cell membranes such as in epithelial and endothelial cells. The first cloned water channel, AQP1, was purified from human erythrocytes by Agre and his associates [1] and its cDNA sequence was reported by Preston and Agre [2]. Then its water transporting capacity was demonstrated by cDNA expression studies in Xenopus oocytes [3]. So far 13 AQPs (AQP0 AQP12) have been cloned and sequenced in mammalian tissues. Each is a small intrinsic membrane protein of molecular weight $\sim 30 \mathrm{kDa}$. These AQPs are classified into two groups: one is water selective channel (orthodox AQPs) and another is water, glycerol, and urea channel (aquaglyceroporins). Among 13 AQPs, AQP4 has a characteristic ultrastructural feature, since AQP4 can be identified by freeze-fracture (F-F) electron microscopy and can be seen as orthogonal arrays (OAs) in this method $[4,5]$. We have so far been studying the pathophysiology of dystrophic muscles at RNA and protein levels including F-F electron microscopy. We found that the densities of both OAs and their subunit particles were reduced in Duchenne muscular dystrophy (DMD) muscles $[6,7]$. So I would like to begin this review from F-F aspect of biological membrane especially focusing on OAs.

\section{Tissue Distribution of Orthogonal Arrays (OAs)}

The cleavage line of F-F goes into hydrophobic interior of biological membrane and F-F technique yields two leaflets of biological membrane: one is protoplasmic $(\mathrm{P})$ face and another is extracellular (E) face [8]. The presence of OAs in cytoplasmic half ( $\mathrm{P}$ face) of frozen cleaved biological plasma membranes has been described in different cell types of different species and different organs and tissues. Those containing OAs in their membranes include epithelial cells of the small intestine [9], brain astrocytes [10,11], skeletal muscle cells [12-14], cardiac muscle cells [15], light cells of the kidney collecting tubules [16], tracheal epithelial 
cells [17], satellite cells of developing spinal ganglia [18], sympathetic ganglia [19], gastric parietal cells [20], olfactory receptor cells of the newt [21], and tanycytes of the organum vasculosum of the lamina terminalis in dog [22]. The functional significance of this specific assembly (OAs) was unknown until Verkman and his coworkers discovered its function as water channel [4, 23-25]. Possible functions thought before the discovery included (1) regulation of membrane permeability $[10,16],(2)$ membrane transport of ions and so on $[10,14,19-22,26],(3)$ regulation of osmotic pressure [21], (4) conduction of activities of epithelial cells [17], (5) cell-to-cell communication [27], (6) adhesive properties [19], and (7) cellular junction [9, 22]. Before the discovery of OAs function as water channel, it was unknown whether the OAs acted as a monofunctional apparatus or one with several functions that differed in different organs and/or tissues.

\section{OAs in Skeletal Muscle}

In skeletal muscle, $\mathrm{P}$ face of muscle plasma membrane contains OAs and E face contains pits of OAs. Sirken and Fischbeck [28] reported that, in normal rat muscle, OAs were virtually absent at birth, but increased steadily from day 1 to day 27. After day 27, the number of OAs declined somewhat, then plateaued. The OA density is the highest at two months after birth in mouse skeletal muscle and, then, decreases gradually after that time [29]. The OA density is reported to be high in fast twitch type 2 myofibers; while it is few in slow twitch type 1 myofibers [30]. In human skeletal muscle, distribution frequency of OAs per square micron in normal muscle plasma membrane showed that almost all myofibers contained the OAs [7]. The age-related changes of OA densities were not studied in human skeletal muscles.

\section{Discovery of Dystrophin and Its Associated Glycoproteins}

DMD is a devastating disorder characterized by severe progressive muscle wasting and cardiac involvement both of which lead to a loss of ambulation by about 11 years of age and death by the third decade, mostly due to cardiac and/or pulmonary insufficiency [31]. Novel studies by Kunkel and his associates cloned the entire cDNA responsible for DMD [32] and determined its complete sequence [33]. The protein product of the cDNA is a large $427-\mathrm{kDa}$ muscle protein that has been named dystrophin [34]. The immunofluorescent studies performed by the several groups of investigators demonstrated the localization of dystrophin at the surface membranes of the normal skeletal myofibers [35-38]. The immunoelectron microscopic investigations revealed the localization of dystrophin along the inner surface of muscle plasma membrane $[39,40]$. Dystrophin constitutes $5 \%$ of membrane cytoskeletons in skeletal muscle [41]. Dystrophin is a membrane cytoskeletal protein anchored to the inner surface of the sarcolemma of normal myofibers by dystrophin-associated glycoproteins (DAGs) [42, 43]. DAGs contain extracellular $\alpha$-dystroglycan, the transmembrane $\beta$ dystroglycan, $\alpha-, \beta-, \gamma-, \delta$-sarcoglycan and sarcospan, and cytoplasmic syntrophins and dystrobrevins [43]. The transmembrane $\beta$-dystroglycan and extracellular $\alpha$-dystroglycan are encoded by a single messenger RNA and are translated inframe from a single $97-\mathrm{kDa}$ precursor protein $[44,45]$. The $\alpha$-dystroglycan binds to laminin of extracellular matrices in muscle and nonmuscle tissue [45]; whereas $\beta$-dystroglycan interacts directly with dystrophin [46]. $\alpha$-, $\beta$-, $\gamma$-, and $\delta$ Sarcoglycans contain one transmembranous domain; while sarcospan has four transmembranous domains [47-52]. Syntrophins and dystrobrevins are the cytoplasmic components of DAGs [43]. Syntrophins contain $\alpha, \beta 1, \beta 2$, $\gamma 1$, and $\gamma^{2}$ isoforms which have been characterized so far $[53,54]$; while dystrobrevins have $\alpha(-1 \sim-5)$ and $\beta$ isoforms [55-58]. Alternative splicing yields five forms of $\alpha$ dystrobrevin, of which two predominate in skeletal muscle: full-length $\alpha$-dystrobrevin-1 $(84 \mathrm{kDa})$, and C-terminal truncated $\alpha$-dystrobrevin-2 (65kDa) [57]. $\alpha$-Dystrobrevin-2, short isoform, binds dystrophin; whereas $\alpha$-dystrobrevin-1 binds both dystrophin and utrophin [57]. Among five syntrophin isoforms, $\alpha 1$-syntrophin is present at its highest levels in skeletal muscle $[59,60]$ where it is located close to the inner surface of muscle plasma membrane together with $\beta 1$-syntrophin. In contrast, $\beta 2$-syntrophin is mainly concentrated at the neuromuscular junction [61]. AQP4 molecule turned out to be associated with $\alpha 1$-syntrophin as described below, although the association is not always the case.

\section{Discovery of AQP4 and Its Relation to OAs}

In 1995, Frigeri et al. [24] proposed that the OAs seen in FF electron microscopy are AQP4. Then Yang et al. [25] first demonstrated that OAs are AQP4. Finally Verbavatz et al. [4] showed that OAs are absent in AQP4 knockout mouse. In central nervous tissues, astroglial endfeet membranes contain numerous OAs. Rash et al. [62] described that the direct immunogold labeling of AQP4 was observed in OAs of astrocyte and ependymocyte plasma membranes in rat brain and spinal cord. In skeletal muscle, Shibuya et al. [63] reported that anti-AQP4 antibody labeled OAs in the plasma membrane of normal rat skeletal myofiber by using fracture label electron microscopy.

\section{AQP4 Binds to $\alpha$-Syntrophin}

$\alpha 1$-Syntrophin knockout mice do not reveal any abnormal clinical phenotype and their skeletal muscles do not show pathological features in hematoxylin-eosin staining specimens. However, their muscle specimens with antiAQP4 antibody immunostaining did not reveal any positive immunoreactivity $[64,65]$. Adams et al. [66] thought that the C-terminal amino acid sequence of AQP4 is-VLSSV which is a potential class I PDZ domain interaction sequence. So they generated transgenic mice to determine whether the membrane localization of AQP4 depended on a syntrophin PDZ domain. Using their mice, they found that AQP4 was 


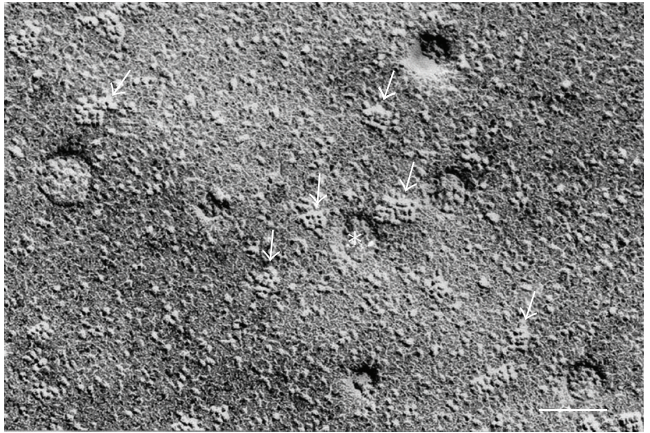

(a)

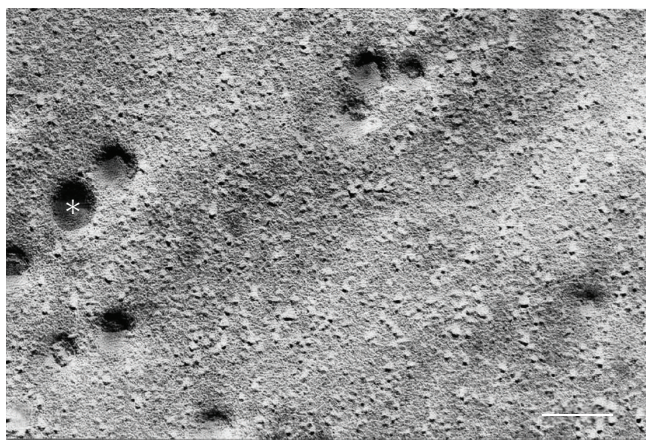

(b)

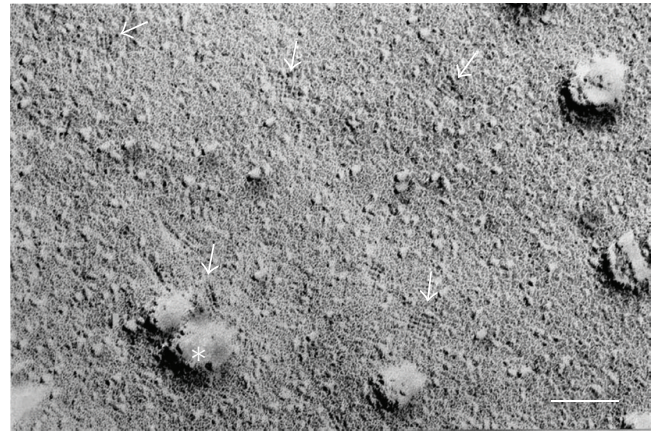

(c)

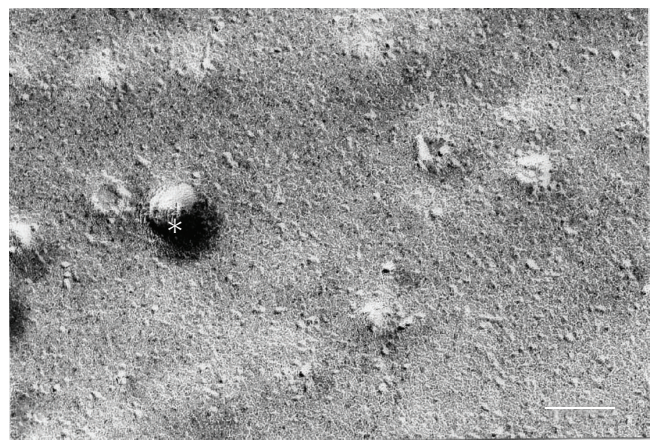

(d)

FIGURE 1: High magnification freeze-fracture view of muscle plasma membrane P faces (a) and (b) and E faces (c) and (d). Normal control muscle contains numerous orthogonal arrays (arrows in (a)) and their pits (arrows in (c)); while Duchenne muscular dystrophy muscle contains apparently no orthogonal arrays (b) and their pits (d). Asterisk in (a)-(d) is caveolae. Scale bar in (a) $-(\mathrm{d})=0.1 \mu \mathrm{m}$.

absent from the sarcolemma and thought that the syntrophin PDZ domain is likely involved in targeting or stabilizing AQP4 [66]. Amiry-Moghaddam et al. [67] studied mice homozygous for targeted disruption of the gene encoding $\alpha$-syntrophin $\left(\alpha\right.$-Syn $\left.{ }^{-/}\right)$and also found that these mice showed a marked loss of AQP4 from perivascular and subpial membranes but no decrease in other membrane domains [67]. In addition, Au et al. [68] described that AQP4 loss did not always correlate with loss of $\alpha$-syntrophin in muscle disease. Based on these reports, it is suggested that AQP4 is associated with $\alpha$-syntrophin, although this association is not always the case.

\section{OAs and AQP4 Expression in Diseased Muscles and Muscles of Animal Models}

The myofiber plasma membrane of DMD was thought to be fragile [69] and, in fact, the plasma membrane defect of DMD myofiber was demonstrated by electron microscopic observations [70-72]. So expression and distribution frequency of OAs in the diseased muscles were the interesting research subject at that time. Those of DMD were well analyzed $[6,73,74]$. The F-F findings of DMD muscle plasma membrane were the decreased density of individual intramembranous particles as well as OAs, or the loss of OAs $[6,33,34]$ (Figure 1). The subunit particles constituting OAs were also reduced in the muscle plasma membrane of
DMD [7]. Similar findings were recognized in the muscle plasma membrane of Fukuyama type congenital muscular dystrophy (FCMD) [75]. The muscle plasma membranes with Becker muscular dystrophy also showed the decrease of OA density. In the muscles of the mdx mouse, the mouse model of $\mathrm{DMD}$, the muscle plasma membranes revealed the decrease of OA density but there was less conspicuous depletion of the individual intramembranous particles [76, 77]. The depletion of OAs was also seen in the muscle plasma membranes of dy/dy mice [78] and dystrophin exon 52 knockout mice [79]. In the denervated muscles, the muscle plasma membranes with early to moderate stage of amyotrophic lateral sclerosis (ALS) contained the substantial number of OAs [35]. Although the F-F study of muscle plasma membranes with advanced stage of ALS has not been reported, the muscle plasma membranes of advanced stage of ALS may have few OAs, since the rat muscles with early denervation contained no OAs [28]. DMD is a major type of human muscular dystrophy and AQP4 expression in DMD muscles has been intensively investigated. Three groups of investigators $[68,80,81]$ reported the results of AQP4 expression of DMD muscles and those of $\mathrm{mdx}$ mouse muscles have also been described $[82,83]$. All reports described that the AQP4 protein expression was reduced in the muscles of DMD boys (Figure 2) and $\mathrm{mdx}$ mice by immunohistochemistry. At RNA level, the results of the relative AQP4 mRNA contents of muscles with DMD boys [68, 81] and mdx mice [83] were somewhat different. 


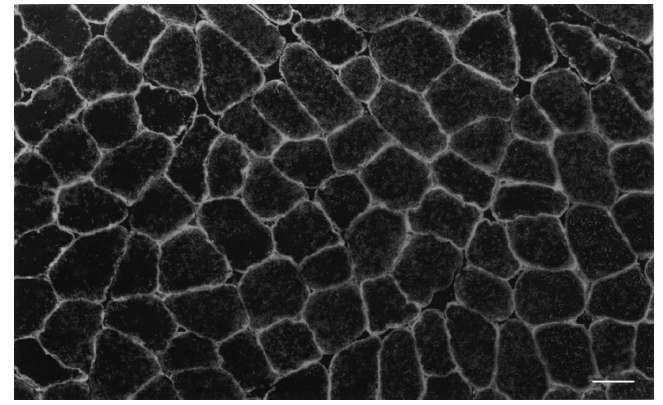

(a)

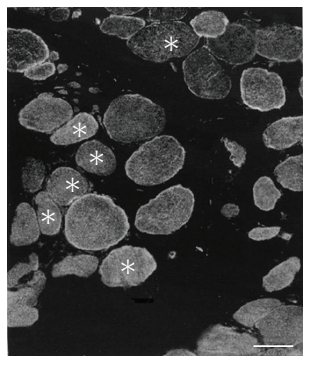

(b)

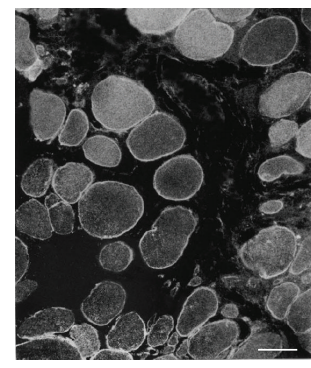

(c)
FIgURE 2: Immunofluorescence with anti-AQP4 antibody of normal control muscle (a) and Duchenne muscular dystrophy muscle (DMD) (b), and that with anti-spectrin antibody of serial muscle section of DMD (c). Positive immunoreactivity with antiAQP4 antibody is seen in apparently all myofibers of normal control muscles (a); while it is noted in mosaic pattern in DMD muscle (b). DMD muscle contains less numerous myofibers with positive immunoreactivity of anti-AQP4 antibody (b) than myofibers with that of anti-spectrin antibody (c). Scattered antiAQP4 immunonegative fibers (asterisks in (b)) are noted in DMD muscle. Scale bar in (a) $-(\mathrm{c})=50 \mu \mathrm{m}$.

We [81] and Au et al. [68] reported the decreased contents of AQP4 mRNA in DMD muscles; while Frigeri et al. [83] reported the normal level of AQP4 mRNA content of mdx mouse muscles and described that the decreased total content of AQP4 protein was not at transcriptional level. Au et al. [68] conducted the immunohistochemistry of AQP4 in the cultured DMD muscle cells and found the normal expression of AQP4. So they suggested that the reduced expression of AQP4 in DMD muscles was secondary to dystrophic process. Reduced AQP4 expression was also reported in severe muscular dystrophies such as FCMD [84], limb girdle muscular dystrophy (LGMD) type 2B [68, 85], sarcoglycanopathies [85], and animal models of sarcoglycanopathies [86]. However, in immunofluorescence analysis, AQP4 was reported to be expressed normally at the sarcolemma of biopsy samples from LGMD type 1C and facioscapulohumeral muscular dystrophy [80]. Many investigations revealed that the muscle contractile cycle appears to be associated with water entry into and exit out of the muscle cell $[87,88]$. Muscle contraction needs energy supply which depends on anaerobic glycolysis in the fast twitch type 2 myofibers. The end product of anaerobic glycolysis is lactate and an increase of lactate by exercise promps a rapid flux of water from the vascular compartment. The fast twitch type 2 myofibers contain many OAs (AQP4) in their sarcolemmal plasma membranes. The water molecule passes the cell membrane very rapidly through AQP4 water channel [89]. This water displacement may affect the membrane potential and thus muscle membrane excitability. Thus AQP4 is suggested to play a role in determining a rapid osmotic transfer of water from blood to muscle cell during muscle contraction. The dystrophic muscle immunohistochemistry tends to show the slow twitch type 1 fiber predominance. Slow twitch type 1 fiber contains less numerous OAs (AQP4) in the sarcolemmal plasma membrane. The decreased expression of AQP4 in the diseased muscles may relate to the slow contraction of voluntary muscles and thus, in part, may have relation to the slow motion of the myopathic patients, although the patient's slowness mostly results from their muscle weakness. The defective expression of AQP4 in FCMD muscles may be based on the reduced expression of $\alpha 1$ syntrophin, which binds to AQP4, in FCMD muscles [90]. The central part of FCMD pathophysiology is the defective glycosylation of $\alpha$-dystroglycan [91], however, the decreased expression of $\alpha 1$-syntrophin in FCMD muscles is reported to be due to the retarded maturation of FCMD muscles [91]. Reduced density of OAs was also reported in Becker muscular dystrophy (BMD) muscles and this reduction was correlated to the severity of BMD [92]. Furthermore, AQP4 expression of muscles with neurogenic muscular atrophy such as ALS was studied by Jimi et al. [93]. They reported that reduced expression of AQP4 was detected in ALS muscles. This phenomenon is confirmed by experimental studies $[28,94]$. The implication of decreased AQP4 expression in the muscles of human muscular dystrophies and neurogenic atrophy is unknown. Animal models such as AQP4 knockout mice [95] and AQP4 overexpressing mice [96] showed no abnormal clinical phenotype. In dy/dy (laminin 2 deficient) mice, the reduction of OAs in the muscle plasma membrane was more marked than that of mdx mice [78].

\section{Other AQPs Expressed in Sarcolemma}

The presence of AQP1, 3, 4 mRNAs in skeletal muscle has been described [97-99]. Further Wang et al. [100] reported that they detected the mRNAs of AQP1, 3, 4, 7, 8, 9, and 10 in human masseter muscle and those of AQP1, 3, 4, and 10 in human infrahyoid muscle by RT-PCR. However, these AQPs mRNA expressions were considered to be the contamination of blood vessels (AQP1), adipocytes (AQP7), and leukocytes (AQP9) in skeletal muscle tissues [95]. To rule out this possibility, we and others conducted the immunocytochemical investigation of AQP1, 3, 5, 7, 9 of skeletal muscles, and confirmed the presence of these AQPs [101-105]. However, AQP1, 7 expression of normal skeletal myofiber is controversial. The negative immunostainings of AQP1 [106] and AQP7 [107] were described at the plasma membrane of skeletal myofiber, although the AQP1 and AQP7 immunoreactivities were recognized at the endothelial cells of endomysial blood vessels. We [104] and Au et al. [68] have performed the immunohistochemical study of AQP1 
in the skeletal muscle and showed the presence of AQP1 at the muscle membrane as well as the endothelial cells of endomysial blood vessels. With regard to AQP1 expression in the DMD muscles, Au et al. [68] reported that AQP1 transcript and protein expression was significantly elevated in DMD biopsies and was localized to the sarcolemma of muscle fibers and endothelia of muscle capillaries. The functional significance of aquaglyceroporins in skeletal muscle is unknown, however, these aquaglyceroporins function as a glycerol channel and may relate to the lipid metabolism in skeletal myofibers [108, 109].

\section{Triglyceride Utilization and Its Possible Aquaglyceroporin Participation in Skeletal Muscle}

The intracellular triglyceride in liver and skeletal muscle has a metabolic importance $[110,111]$. Fatty acids of muscle triglyceride are derived from both circulating lipoprotein-triglyceride and free fatty acid which comes at least partially from adipose tissue lipolysis [110]. Lipolysis of circulating lipoprotein-triglyceride occurs in the capillary lumen prior to cellular uptake of fatty acids [110]. This extracellular lipolysis is controlled by lipoprotein lipase which is associated with the luminal side of the capillary endothelium. Lipoprotein lipase is activated by circulating apolipoprotein CII and inhibited by apolipoprotein CIII [110]. Adipose tissue lipoprotein lipase activity is the greatest [112] and is reciprocally regulated by hormonesensitive lipase [113]. Adipose tissue lipoprotein lipase activity has diurnal fluctuation and is most active postprandially for the aim of fatty acids uptake for storage; while its activity decreases when there is a flux of fatty acids from adipose tissue such as the case in fasting [114]. In lipogenic conditions, intracellular glucose is converted by glycerol kinase to glycerol-3-phosphate which is then esterified into triglycerides in adipocytes [115].

The discovery of AQPs has greatly influenced the medical sciences. AQP3, 7, 9, and 10 are subcategorized as aquaglyceroporins, which transport the glycerol in addition to water. Adipocytes are a major source of glycerol which is one of the substrates for hepatic gluconeogenesis [115]. AQP7 and 9 are the glycerol channels in adipocytes and hepatocytes, respectively, [115]. Recently AQP9 is reported to be expressed weakly at the surface membrane of skeletal myofibers [105]. Hepatocytes and myocytes are two major insulin-sensitizing cells [115]. Through AQP7, the hydrolyzed glycerol is efficiently released from adipocytes into the blood stream. AQP7 mRNA levels in adipose tissue are reduced by feeding and increased by fasting in opposite to the changes in plasma insulin levels. Insulin suppresses AQP7 mRNA levels through the insulin negative element located on the promoter region of the AQP7 gene [115]. Therefore, plasma glycerol levels are partly determined by the action of insulin in adipose tissue. Thus long-term regulation of AQP7 is controlled by insulin at the transcriptional level; while short-term regulation is under the control of catecholamines [115].
AQP9 is a glycerol channel in liver cells and is localized at the sinusoidal plasma membrane which faces the portal vein [115-118]. On the other hand, weakly expressed skeletal muscle AQP9 is localized at the myofiber surface membrane [105]. AQP9 mRNA levels are increased by fasting and decreased by feeding [115-117], and this pattern of changes is similar to that for glycerol kinase and for phosphoenolpyruvate carboxykinase, the latter of which is a key enzyme in gluconeogenesis [115]. In the feeding state, an elevation of plasma insulin suppresses lipolysis in adipocytes, reduces adipose AQP7 mRNA levels, and lowers the rate of glycerol release; while liver and possibly myocyte AQP9 mRNA levels are reduced, and glycerol-based gluconeogenesis seems to be suppressed [115]. The investigations of aquaglyceroporins' expression including that of AQP9 in the pathological muscles due to endocrine disorders such as muscles with type 2 diabetes mellitus will suggest some in the functional role(s) of muscle aquaglyceroporins in these pathological conditions.

\section{Closing Remarks}

The expression of AQPs in normal skeletal muscles and their altered expression in the diseased muscles so far reported were summarized in this review. The research of AQPs in skeletal muscles has not been done so extensively until now and has just begun in recent years. Further studies will throw light into the functional role(s) of AQP4 and other AQPs in the normal muscle physiology as well as in the pathophysiology of diseased muscles.

\section{Acknowledgments}

This study was partly supported by The Research Grant (20B13) for Nervous and Mental Disorders from the Ministry of Health, Labour and Welfare. Thanks were extended to Mr. Hiroaki Oniki and Mrs. Tomoko Nagami for their kind help.

\section{References}

[1] B. M. Denker, B. L. Smith, F. P. Kuhajda, and P. Agre, "Identification, purification, and partial characterization of a novel $\mathrm{M}_{r}$ 28,000 integral membrane protein from erythrocytes and renal tubules," Journal of Biological Chemistry, vol. 263, no. 30, pp. 15634-15642, 1988.

[2] G. M. Preston and P. Agre, "Isolation of the cDNA for erythrocyte integral membrane protein of 28 kilodaltons: member of an ancient channel family," Proceedings of the National Academy of Sciences of the United States of America, vol. 88, no. 24, pp. 11110-11114, 1991.

[3] G. M. Preston, T. P. Carroll, W. B. Guggino, and P. Agre, "Appearance of water channels in Xenopus oocytes expressing red cell CHIP28 protein," Science, vol. 256, no. 5055, pp. 385-387, 1992.

[4] J.-M. Verbavatz, T. Ma, R. Gobin, and A. S. Verkman, "Absence of orthogonal arrays in kidney, brain and muscle from transgenic knockout mice lacking water channel aquaporin-4," Journal of Cell Science, vol. 110, no. 22, pp. 2855-2860, 1997. 
[5] C. S. Furman, D. A. Gorelick-Feldman, K. G. V. Davidson, et al., "Aquaporin-4 square array assembly: opposing actions of M1 and M23 isoforms," Proceedings of the National Academy of Sciences of the United States of America, vol. 100, no. 23, pp. 13609-13614, 2003.

[6] D. L. Schotland, E. Bonilla, and Y. Wakayama, "Freeze fracture studies of muscle plasma membrane in human muscular dystrophy," Acta Neuropathologica, vol. 54, no. 3, pp. 189-197, 1981.

[7] Y. Wakayama, H. Okayasu, S. Shibuya, and T. Kumagai, "Duchenne dystrophy: reduced density of orthogonal array subunit particles in muscle plasma membrane," Neurology, vol. 34, no. 10, pp. 1313-1317, 1984.

[8] D. Branton, "Fracture faces of frozen membranes," Proceedings of the National Academy of Sciences of the United States of America, vol. 55, no. 5, pp. 1048-1056, 1966.

[9] L. A. Staehelin, "Three types of gap junctions interconnecting intestinal epithelial cells visualized by freeze-etching," Proceedings of the National Academy of Sciences of the United States of America, vol. 69, no. 5, pp. 1318-1321, 1972.

[10] D. M. D. Landis and T. S. Reese, "Arrays of particles in freeze fractured astrocytic membranes," Journal of Cell Biology, vol. 60, no. 1, pp. 316-320, 1974.

[11] D. M. D. Landis and T. S. Reese, "Astrocyte membrane structure: changes after circulatory arrest," Journal of Cell Biology, vol. 88, no. 3, pp. 660-663, 1981.

[12] J. E. Rash and M. H. Ellisman, "Studies of excitable membranes. I. Macromolecular specializations of the neuromuscular junction and the nonjunctional sarcolemma," Journal of Cell Biology, vol. 63, no. 2, part 1, pp. 567-586, 1974.

[13] J. E. Rash, L. A. Staehelin, and M. H. Ellisman, "Rectangular arrays of particles on freeze cleaved plasma membranes are not gap junctions," Experimental Cell Research, vol. 86, no. 1, pp. 187-190, 1974.

[14] H. Schmalbruch, "Square arrays' in the sarcolemma of human skeletal muscle fibres," Nature, vol. 281, no. 5727, pp. 145-146, 1979.

[15] N. S. McNutt, "Ultrastructure of the myocardial sarcolemma," Circulation Research, vol. 37, no. 1, pp. 1-13, 1975.

[16] F. Humbert, C. Pricam, A. Perrelet, and L. Orci, "Specific plasma membrane differentiations in the cells of the kidney collecting tubule," Journal of Ultrastructure Research, vol. 52, no. 1, pp. 13-20, 1975.

[17] S. Inoue and J. C. Hogg, "Freeze etch study of the tracheal epithelium of normal guinea pigs with particular reference to intercellular junctions," Journal of Ultrastructure Research, vol. 61, no. 1, pp. 89-99, 1977.

[18] E. Pannese, L. Luciano, S. Iurato, and E. Reale, "Intercellular junctions and other membrane specializations in developing spinal ganglia: a freeze fracture study," Journal of Ultrastructure Research, vol. 60, no. 2, pp. 169-180, 1977.

[19] L. G. Elfvin and C. Forsman, "The ultrastructure of junctions between satellite cells in mammalian sympathetic ganglia as revealed by freeze-etching," Journal of Ultrastructure Research, vol. 63, no. 3, pp. 261-274, 1978.

[20] C. Bordi and A. Perrelet, "Orthogonal arrays of particles in plasma membranes of the gastric parietal cell," Anatomical Record, vol. 192, no. 2, pp. 297-303, 1978.

[21] J. Usukura and E. Yamada, "Observations on the cytolemma of the olfactory receptor cell in the newt. I. Freeze replica analysis," Cell and Tissue Research, vol. 188, no. 1, pp. 83-98, 1978.
[22] Y. Nakai, J. Kudo, and A. Hashimoto, "Specific cell membrane differentiation in the tanycytes and glial cells of the organum vasculosum of the lamina terminalis in dog," Journal of Electron Microscopy, vol. 29, no. 2, pp. 144-150, 1980.

[23] A. S. Verkman, "Aquaporin water channels and endothelial cell function," Journal of Anatomy, vol. 200, no. 6, pp. 617627, 2002.

[24] A. Frigeri, M. A. Gropper, F. Umenishi, M. Kawashima, D. Brown, and A. S. Verkman, "Localization of MIWC and GLIP water channel homologs in neuromuscular, epithelial and glandular tissues," Journal of Cell Science, vol. 108, no. 9, pp. 2993-3002, 1995.

[25] B. Yang, D. Brown, and A. S. Verkman, "The mercurial insensitive water channel (AQP-4) forms orthogonal arrays in stably transfected Chinese hamster ovary cells," Journal of Biological Chemistry, vol. 271, no. 9, pp. 4577-4580, 1996.

[26] J. D. Hatton and M. H. Ellisman, "The distribution of orthogonal arrays and their relationship to intercellular junctions in neuroglia of the freeze-fractured hypothalamoneurohypophysial system," Cell and Tissue Research, vol. 215, no. 2, pp. 309-323, 1981.

[27] R. Dermietzel, "Visualization by freeze-fracturing of regular structures in glial cell membranes," Naturwissenschaften, vol. 60, no. 4, p. 208, 1973.

[28] S. M. Sirken and K. H. Fischbeck, "Freeze-fracture studies of denervated and tenotomized rat muscle," Journal of Neuropathology and Experimental Neurology, vol. 44, no. 2, pp. 147-155, 1985.

[29] S. Shibuya and Y. Wakayama, "Changes in muscle plasma membranes in young mice with $\mathrm{X}$ chromosome-linked muscular dystrophy: a freeze-fracture study," Neuropathology and Applied Neurobiology, vol. 17, no. 4, pp. 335-344, 1991.

[30] A. Frigeri, G. P. Nicchia, J. M. Verbavatz, G. Valenti, and M. Svelto, "Expression of aquaporin-4 in fast-twitch fibers of mammalian skeletal muscle," Journal of Clinical Investigation, vol. 102, no. 4, pp. 695-703, 1998.

[31] A. G. Engel and E. Ozawa, "Dystrophinopathies," in Myology, A. G. Engel and C. Franzini-Armstrong, Eds., pp. 961-1025, The McGraw-Hill, New York, NY, USA, 2003.

[32] M. Koening, E. P. Hoffman, C. J. Bertelson, A. P. Monaco, C. Feener, and L. M. Kunkel, "Complete cloning of the Duchenne muscular dystrophy (DMD) cDNA and preliminary genomic organization of the DMD gene in normal and affected individuals," Cell, vol. 50, no. 3, pp. 509-517, 1987.

[33] M. Koenig, A. P. Monaco, and L. M. Kunkel, “The complete sequence of dystrophin predicts a rod-shaped cytoskeletal protein," Cell, vol. 53, no. 2, pp. 219-228, 1988.

[34] E. P. Hoffman, R. H. Brown Jr., and L. M. Kunkel, "Dystrophin: the protein product of the Duchenne muscular dystrophy locus," Cell, vol. 51, no. 6, pp. 919-928, 1987.

[35] Y. Wakayama, T. Jimi, N. Misugi, et al., "Dystrophin immunostaining and freeze-fracture studies of muscles of patients with early stage amyotrophic lateral sclerosis and Duchenne muscular dystrophy," Journal of the Neurological Sciences, vol. 91, no. 1-2, pp. 191-205, 1989.

[36] K. Arahata, S. Ishiura, T. Ishiguro, et al., "Immunostaining of skeletal and cardiac muscle surface membrane with antibody against Duchenne muscular dystrophy peptide," Nature, vol. 333, no. 6176, pp. 861-863, 1988.

[37] E. Bonilla, C. E. Samitt, A. F. Miranda, et al., "Duchenne muscular dystrophy: deficiency of dystrophin at the muscle cell suface," Cell, vol. 54, no. 4, pp. 447-452, 1988. 
[38] E. E. Zubrzycka-Gaarn, D. E. Bulman, G. Karpati, et al., "The Duchenne muscular dystrophy gene product is localized in sarcolemma of human skeletal muscle," Nature, vol. 333, no. 6172, pp. 466-469, 1988.

[39] S. C. Watkins, E. P. Hoffman, H. S. Slayter, and L. M. Kunkel, "Immunoelectron microscopic localization of dystrophin in myofibres," Nature, vol. 333, no. 6176, pp. 863-866, 1988.

[40] Y. Wakayama and S. Shibuya, "Observations on the muscle plasma membrane-associated cytoskeleton of mdx mice by quick-freeze, deep-etch, rotary-shadow replica method," Acta Neuropathologica, vol. 80, no. 6, pp. 618-623, 1990.

[41] K. Ohlendieck and K. P. Campbell, "Dystrophin constitutes $5 \%$ of membrane cytoskeleton in skeletal muscle," FEBS Letters, vol. 283, no. 2, pp. 230-234, 1991.

[42] J. M. Ervasti, K. Ohlendieck, S. D. Kahl, M. G. Gaver, and K. P. Campbell, "Deficiency of a glycoprotein component of the dystrophin complex in dystrophic muscle," Nature, vol. 345, no. 6273 , pp. 315-319, 1990.

[43] E. Ozawa, "The muscle fiber cytoskeleton: the dystrophin system," in Myology, A. G. Engel and C. Franzini-Armstrong, Eds., pp. 455-470, The McGraw-Hill, New York, NY, USA, 2003.

[44] O. Ibraghimov-Beskrovnaya, J. M. Ervasti, C. J. Leveille, C. A. Slaughter, S. W. Sernett, and K. P. Campbell, "Primary structure of dystrophin-associated glycoproteins linking dystrophin to the extracellular matrix," Nature, vol. 355, no. 6362, pp. 696-702, 1992.

[45] O. Ibraghimov-Beskrovnaya, A. Milatovich, T. Ozcelik, et al., "Human dystroglycan: skeletal muscle cDNA, genomic structure, origin of tissue specific isoforms and chromosomal localization," Human Molecular Genetics, vol. 2, no. 10, pp. 1651-1657, 1993.

[46] A. Suzuki, M. Yoshida, K. Hayashi, Y. Mizuno, Y. Hagiwara, and E. Ozawa, "Molecular organization at the glycoproteincomplex-binding site of dystrophin-three dystrophinassociated proteins bind directly to the carboxy-terminal portion of dystrophin," European Journal of Biochemistry, vol. 220, no. 2, pp. 283-292, 1994.

[47] S. L. Roberds, R. D. Anderson, O. Ibraghimov-Beskrovnaya, and K. P. Campbell, "Primary structure and muscle-specific expression of the 50-kDa dystrophin-associated glycoprotein (adhalin)," Journal of Biological Chemistry, vol. 268, no. 32, pp. 23739-23742, 1993.

[48] C. G. Bönnemann, R. Modi, S. Noguchi, et al., “ $\beta$-sarcoglycan (A3b) mutations cause autosomal recessive muscular dystrophy with loss of the sarcoglycan complex," Nature Genetics, vol. 11, no. 3, pp. 266-273, 1995.

[49] L. E. Lim, F. Duclos, O. Broux, et al., " $\beta$-sarcoglycan: characterization and role in limb-girdle muscular dystrophy linked to 4q12," Nature Genetics, vol. 11, no. 3, pp. 257-265, 1995.

[50] S. Noguchi, E. M. McNally, K. Ben Othmane, et al., "Mutations in the dystrophin-associated protein $\gamma$ sarcoglycan in chromosome 13 muscular dystrophy," Science, vol. 270, no. 5237, pp. 819-822, 1995.

[51] V. Nigro, G. Piluso, A. Belsito, et al., "Identification of a novel sarcoglycan gene at $5 \mathrm{q} 33$ encoding a sarcolemmal $35 \mathrm{kDa}$ glycoprotein," Human Molecular Genetics, vol. 5, no. 8, pp. 1179-1186, 1996.

[52] R. H. Crosbie, J. Heighway, D. P. Venzke, J. C. Lee, and K. P. Campbell, "Sarcospan, the $25-\mathrm{kDa}$ transmembrane component of the dystrophin-glycoprotein complex," Journal of Biological Chemistry, vol. 272, no. 50, pp. 31221-31224, 1997.
[53] A. H. Ahn, C. A. Freener, E. Gussoni, M. Yoshida, E. Ozawa, and L. M. Kunkel, "The three human syntrophin genes are expressed in diverse tissues, have distinct chromosomal locations, and each bind to dystrophin and its relatives," Journal of Biological Chemistry, vol. 271, no. 5, pp. 27242730, 1996.

[54] G. Piluso, M. Mirabella, E. Ricci, et al., " $\gamma 1$ - and $\gamma 2$ syntrophins, two novel dystrophin-binding proteins localized in neuronal cells," Journal of Biological Chemistry, vol. 275, no. 21, pp. 15851-15860, 2000.

[55] D. J. Blake, R. Nawrotzki, M. F. Peters, S. C. Froehner, and K. E. Davies, "Isoform diversity of dystrobrevin, the murine 87$\mathrm{kDa}$ postsynaptic protein," Journal of Biological Chemistry, vol. 271, no. 13, pp. 7802-7810, 1996.

[56] M. F. Peters, K. F. O’Brien, H. M. Sadoulet-Puccio, L. M. Kunkel, M. E. Adams, and S. C. Froehner, " $\beta$-dystrobrevin, a new member of the dystrophin family: identification, cloning, and protein associations," Journal of Biological Chemistry, vol. 272, no. 50, pp. 31561-31569, 1997.

[57] M. F. Peters, H. M. Sadoulet-Puccio, M. R. Grady, et al., "Differential membrane localization and intermolecular associations of $\alpha$-dystrobrevin isoforms in skeletal muscle," Journal of Cell Biology, vol. 142, no. 5, pp. 1269-1278, 1998.

[58] R. M. Grady, R. W. Grange, K. S. Lau, et al., "Role for $\alpha$ dystrobrevin in the pathogenesis of dystrophin-dependent muscular dystrophies," Nature Cell Biology, vol. 1, no. 4, pp. 215-220, 1999.

[59] M. E. Adams, M. H. Butler, T. M. Dwyer, M. F. Peters, A. A. Murnane, and S. C. Froehner, "Two forms of mouse syntrophin, a $58 \mathrm{kd}$ dystrophin-associated protein, differ in primary structure and tissue distribution," Neuron, vol. 11, no. 3, pp. 531-540, 1993.

[60] M. Durbeej and K. P. Campbell, "Muscular dystrophies involving the dystrophin-glycoprotein complex: an overview of current mouse models," Current Opinion in Genetics \& Development, vol. 12, no. 3, pp. 349-361, 2002.

[61] M. F. Peters, N. R. Kramarcy, R. Sealock, and S. C. Froehner, " $\beta 2$-syntrophin: localization at the neuromuscular junction in skeletal muscle," NeuroReport, vol. 5, no. 13, pp. 15771580, 1994.

[62] J. E. Rash, T. Yasumura, C. S. Hudson, P. Agre, and S. Nielsen, "Direct immunogold labeling of aquaporin-4 in square arrays of astrocyte and ependymocyte plasma membranes in rat brain and spinal cord," Proceedings of the National Academy of Sciences of the United States of America, vol. 95, no. 20, pp. 11981-11986, 1998.

[63] S. Shibuya, Y. Wakayama, and M. Inoue, "Identification of aquaporin 4 molecule in the replica of normal rat sarcolemma: fracture-label immnoelectron microscopic study," Annals of Neurology, vol. 46, p. 460, 1999.

[64] S. Kameya, Y. Miyagoe, I. Nonaka, et al., " $\alpha 1$-syntrophin gene disruption results in the absence of neuronal-type nitricoxide synthase at the sarcolemma but does not induce muscle degeneration," Journal of Biological Chemistry, vol. 274, no. 4, pp. 2193-2200, 1999.

[65] T. Yokota, Y. Miyagoe, Y. Hosaka, et al., "Aquaporin-4 is absent at the sarcolemma and at perivascular astrocyte endfeet in $\alpha 1$-syntrophin knockout mice," Proceedings of the Japan Academy Series B, vol. 76, no. 2, pp. 22-27, 2000.

[66] M. E. Adams, H. A. Mueller, and S. C. Froehner, "In vivo requirement of the $\alpha$-syntrophin PDZ domain for the sarcolemmal localization of nNOS and aquaporin-4," Journal of Cell Biology, vol. 155, no. 1, pp. 113-122, 2001. 
[67] M. Amiry-Moghaddam, T. Otsuka, P. D. Hurn, et al., "An $\alpha$-syntrophin-dependent pool of AQP4 in astroglial end-feet confers bidirectional water flow between blood and brain," Proceedings of the National Academy of Sciences of the United States of America, vol. 100, no. 4, pp. 2106-2111, 2003.

[68] C. G. Au, T. L. Butler, J. R. Egan, et al., "Changes in skeletal muscle expression of AQP1 and AQP4 in dystrophinopathy and dysferlinopathy patients," Acta Neuropathologica, vol. 116, no. 3, pp. 235-246, 2008.

[69] L. P. Rowland, "Pathogenesis of muscular dystrophies," Archives of Neurology, vol. 33, no. 5, pp. 315-321, 1976.

[70] B. Mokri and A. G. Engel, "Duchenne dystrophy: electron microscopic findings pointing to a basic or early abnormality in the plasma membrane of the muscle fiber," Neurology, vol. 25, no. 12, pp. 1111-1120, 1975.

[71] H. Schmalbruch, "Segmental fibre breakdown and defects of the plasmalemma in diseased human muscles," Acta Neuropathologica, vol. 33, no. 2, pp. 129-141, 1975.

[72] Y. Wakayama, E. Bonilla, and D. L. Schotland, "Muscle plasma membrane abnormalities in infants with Duchenne muscular dystrophy," Neurology, vol. 33, no. 10, pp. 13681370, 1983.

[73] D. L. Schotland, E. Bonilla, and M. Van Meter, "Duchenne dystrophy: alteration in muscle plasma membrane structure," Science, vol. 196, no. 4293, pp. 1005-1007, 1977.

[74] D. Peluchetti, M. Mora, A. Protti, and F. Cornelio, "Freezefracture analysis of the muscle fiber plasma membrane in Duchenne dystrophy," Neurology, vol. 35, no. 6, pp. 928-930, 1985.

[75] Y. Wakayama, T. Kumagai, and S. Shibuya, "Freeze-fracture studies of muscle plasma membrane in Fukuyama-type congenital muscular dystrophy," Neurology, vol. 35, no. 11, pp. 1587-1593, 1985.

[76] S. Shibuya and Y. Wakayama, "Freeze-fracture studies of myofiber plasma membrane in X chromosome-linked muscular dystrophy (mdx) mice," Acta Neuropathologica, vol. 76, no. 2, pp. 179-184, 1988.

[77] H. Ito, T. Yoshimura, M. Tsujihata, and S. Nagataki, "Distribution of intramembranous particle size in the muscle plasma membrane of the $\mathrm{mdx}$ mouse," Journal of the Neurological Sciences, vol. 148, no. 2, pp. 147-151, 1997.

[78] S. Shibuya, Y. Wakayama, H. Oniki, et al., "A comparative freeze-fracture study of plasma membrane of dystrophic skeletal muscles in dy/dy mice with merosin (laminin 2) deficiency and mdx mice with dystrophin deficiency," Neuropathology and Applied Neurobiology, vol. 23, no. 2, pp. 123-131, 1997.

[79] S. Shibuya, Y. Wakayama, M. Murahashi, et al., "Muscle plasma membrane changes in dystrophin gene exon 52 knockout mouse," Pathology Research and Practice, vol. 197, no. 6, pp. 441-447, 2001.

[80] A. Frigeri, G. P. Nicchia, S. Repetto, M. Bado, C. Minetti, and M. Svelto, "Altered aquaporin-4 expression in human muscular dystrophies: a common feature?" The FASEB Journal, vol. 16, no. 9, pp. 1120-1122, 2002.

[81] Y. Wakayama, T. Jimi, M. Inoue, et al., "Reduced aquaporin 4 expression in the muscle plasma membrane of patients with Duchenne muscular dystrophy," Archives of Neurology, vol. 59, no. 3, pp. 431-437, 2002.

[82] J. W. Liu, Y. Wakayama, M. Inoue, et al., "Immunocytochemical studies of aquaporin 4 in the skeletal muscle of $\mathrm{mdx}$ mouse," Journal of the Neurological Sciences, vol. 164, no. 1, pp. 24-28, 1999.
[83] A. Frigeri, G. P. Nicchia, B. Nico, et al., "Aquaporin-4 deficiency in skeletal muscle and brain of dystrophic mdx mice," The FASEB Journal, vol. 15, no. 1, pp. 90-98, 2001.

[84] Y. Wakayama, T. Jimi, M. Inoue, et al., "Altered aquaporin 4 expression in muscles of Fukuyama-type congenital muscular dystrophy," Virchows Archiv, vol. 443, no. 6, pp. 761-767, 2003.

[85] S. Assereto, M. Mastrototaro, S. Stringara, et al., "Aquaporin4 expression is severely reduced in human sarcoglycanopathies and dysferlinopathies," Cell Cycle, vol. 7, no. 14, pp. 2199-2207, 2008.

[86] R. H. Crosbie, S. A. Dovico, J. D. Flanagan, J. S. Chamberlain, C. L. Ownby, and K. P. Campbell, "Characterization of aquaporin-4 in muscle and muscular dystrophy," The FASEB Journal, vol. 16, no. 9, pp. 943-949, 2002.

[87] G. Sjøgaard, R. P. Adams, and B. Saltin, "Water and ion shifts in skeletal muscle of humans with intense dynamic knee extension," American Journal of Physiology, vol. 248, no. 2, part 2, pp. R190-R196, 1985.

[88] J. M. Kowalchuk, G. J. F. Heigenhauser, M. I. Lindinger, J. R. Sutton, and N. L. Jones, "Factors influencing hydrogen ion concentration in muscle after intense exercise," Journal of Applied Physiology, vol. 65, no. 5, pp. 2080-2089, 1988.

[89] Y. Hiroaki, K. Tani, A. Kamegawa, et al., "Implications of the aquaporin-4 structure on array formation and cell adhesion," Journal of Molecular Biology, vol. 355, no. 4, pp. 628-639, 2006.

[90] Y. Wakayama, M. Inoue, H. Kojima, et al., "Altered $\alpha 1$ syntrophin expression in myofibers with Duchenne and Fukuyama muscular dystrophies," Histology and Histopathology, vol. 21, no. 1, pp. 23-34, 2006.

[91] Y. Wakayama, M. Inoue, H. Kojima, et al., "Reduced expression of sarcospan in muscles of Fukuyama congenital muscular dystrophy," Histology and Histopathology, vol. 23, no. 12, pp. 1425-1438, 2008.

[92] S. Shibuya, Y. Wakayama, T. Jimi, et al., "Freeze-fracture analysis of muscle plasma membrane in Becker's muscular dystrophy," Neuropathology and Applied Neurobiology, vol. 20, no. 5, pp. 487-494, 1994.

[93] T. Jimi, Y. Wakayama, Y. Matsuzaki, H. Hara, M. Inoue, and S. Shibuya, "Reduced expression of aquaporin 4 in human muscles with amyotrophic lateral sclerosis and other neurogenic atrophies," Pathology Research and Practice, vol. 200, no. 3, pp. 203-209, 2004.

[94] T. Jimi and Y. Wakayama, "Effect of denervation on regenerating muscle plasma membrane integrity: freeze-fracture and dystrophin immunostaining analyses," Acta Neuropathologica, vol. 80, no. 4, pp. 401-405, 1990.

[95] B. Yang, J.-M. Verbavatz, Y. Song, et al., "Skeletal muscle function and water permeability in aquaporin-4 deficient mice," American Journal of Physiology. Cell Physiology, vol. 278, no. 6, pp. C1108-C1115, 2000.

[96] Y. Wakayama, J. Takahashi, S. Shibuya, et al., "Generation of muscle aquaporin 4 overexpressing transgenic mouse: its characterization at RNA and protein levels including freezefracture study," Micron, vol. 38, no. 3, pp. 257-267, 2007.

[97] T. Ma, A. Frigeri, H. Hasegawa, and A. S. Verkman, "Cloning of a water channel homolog expressed in brain meningeal cells and kidney collecting duct that functions as a stilbene-sensitive glycerol transporter," Journal of Biological Chemistry, vol. 269, no. 34, pp. 21845-21849, 1994. 
[98] F. Umenishi, A. S. Verkman, and M. A. Gropper, "Quantitative analysis of aquaporin mRNA expression in rat tissues by RNase protection assay," DNA and Cell Biology, vol. 15, no. 6, pp. 475-480, 1996.

[99] A. Mobasheri, S. Wray, and D. Marples, "Distribution of AQP2 and AQP3 water channels in human tissue microarrays," Journal of Molecular Histology, vol. 36, no. 1-2, pp. 1$14,2005$.

[100] W. Wang, P. S. Hart, N. P. Piesco, X. Lu, M. C. Gorry, and T. C. Hart, "Aquaporin expression in developing human teeth and selected orofacial tissues," Calcified Tissue International, vol. 72, no. 3, pp. 222-227, 2003.

[101] S. M. Hwang, R. H. Lee, J. M. Song, et al., "Expression of aquaporin-5 and its regulation in skeletal muscle cells," Experimental \& Molecular Medicine, vol. 34, no. 1, pp. 69-74, 2002.

[102] Y. Wakayama, T. Jimi, M. Inoue, et al., "Expression of aquaporin 3 and its localization in normal skeletal myofibres," Histochemical Journal, vol. 34, no. 6-7, pp. 331-337, 2002.

[103] Y. Wakayama, M. Inoue, H. Kojima, et al., "Expression and localization of aquaporin 7 in normal skeletal myofiber," Cell and Tissue Research, vol. 316, no. 1, pp. 123-129, 2004.

[104] T. Jimi, Y. Wakayama, M. Inoue, et al., "Aquaporin 1: examination of its expression and localization in normal human skeletal muscle tissue," Cells Tissues Organs, vol. 184, no. 3-4, pp. 181-187, 2006.

[105] M. Inoue, Y. Wakayama, H. Kojima, et al., "Aquaporin 9 expression and its localization in normal skeletal myofiber," Journal of Molecular Histology, vol. 40, no. 3, pp. 165-170, 2009.

[106] A. Frigeri, G. P. Nicchia, R. Balena, B. Nico, and M. Svelto, "Aquaporins in skeletal muscle: reassessment of the functional role of aquaporin-4," The FASEB Journal, vol. 18, no. 7, pp. 905-907, 2004.

[107] M. T. Skowronski, J. Lebeck, A. Rojek, et al., "AQP7 is localized in capillaries of adipose tissue, cardiac and striated muscle: implications in glycerol metabolism," American Journal of Physiology. Renal Physiology, vol. 292, no. 3, pp. F956-F965, 2007.

[108] E. A. Newsholme and K. Taylor, "Glycerol kinase activities in muscles from vertebrates and invertebrates," Biochemical Journal, vol. 112, no. 4, pp. 465-474, 1969.

[109] N. Maeda, T. Hibuse, and T. Funahashi, "Role of aquaporin7 and aquaporin-9 in glycerol metabolism; involvement in obesity," Handbook of Experimental Pharmacology, no. 190, pp. 233-249, 2009.

[110] G. R. Dagenais, R. G. Tancredi, and K. L. Zierler, "Free fatty acid oxidation by forearm muscle at rest, and evidence for an intramuscular lipid pool in the human forearm," Journal of Clinical Investigation, vol. 58, no. 2, pp. 421-431, 1976.

[111] S. W. Coppack, M. D. Jensen, and J. M. Miles, "In vivo regulation of lipolysis in humans," Journal of Lipid Research, vol. 35, no. 2, pp. 177-193, 1994.

[112] R. H. Eckel, "Lipoprotein lipase: a multifunctional enzyme relevant to common metabolic diseases," The New England Journal of Medicine, vol. 320, no. 16, pp. 1060-1068, 1989.

[113] D. Steinberg and J. C. Khoo, "Hormone-sensitive lipase of adipose tissue," Federation Proceedings, vol. 36, no. 7, pp. 1986-1990, 1977.

[114] H. Lithell, J. Boberg, K. Hellsing, G. Lundqvist, and B. Vessby, "Lipoprotein lipase activity in human skeletal muscle and adipose tissue in the fasting and the fed states," Atherosclerosis, vol. 30, no. 1, pp. 89-94, 1978.
[115] N. Maeda, T. Funahashi, and I. Shimomura, "Metabolic impact of adipose and hepatic glycerol channels aquaporin 7 and aquaporin 9," Nature Clinical Practice Endocrinology \& Metabolism, vol. 4, no. 11, pp. 627-634, 2008.

[116] H. Kuriyama, I. Shimomura, K. Kishida, et al., "Coordinated regulation of fat-specific and liver-specific glycerol channels, aquaporin adipose and aquaporin 9," Diabetes, vol. 51, no. 10, pp. 2915-2921, 2002.

[117] J. M. Carbrey, D. A. Gorelick-Feldman, D. Kozono, J. Praetorius, S. Nielsen, and P. Agre, "Aquaglyceroporin AQP9: solute permeation and metabolic control of expression in liver," Proceedings of the National Academy of Sciences of the United States of America, vol. 100, no. 5, pp. 2945-2950, 2003.

[118] P. Portincasa, G. Palasciano, M. Svelto, and G. Calamita, "Aquaporins in the hepatobiliary tract. Which, where and what they do in health and disease," European Journal of Clinical Investigation, vol. 38, no. 1, pp. 1-10, 2008. 

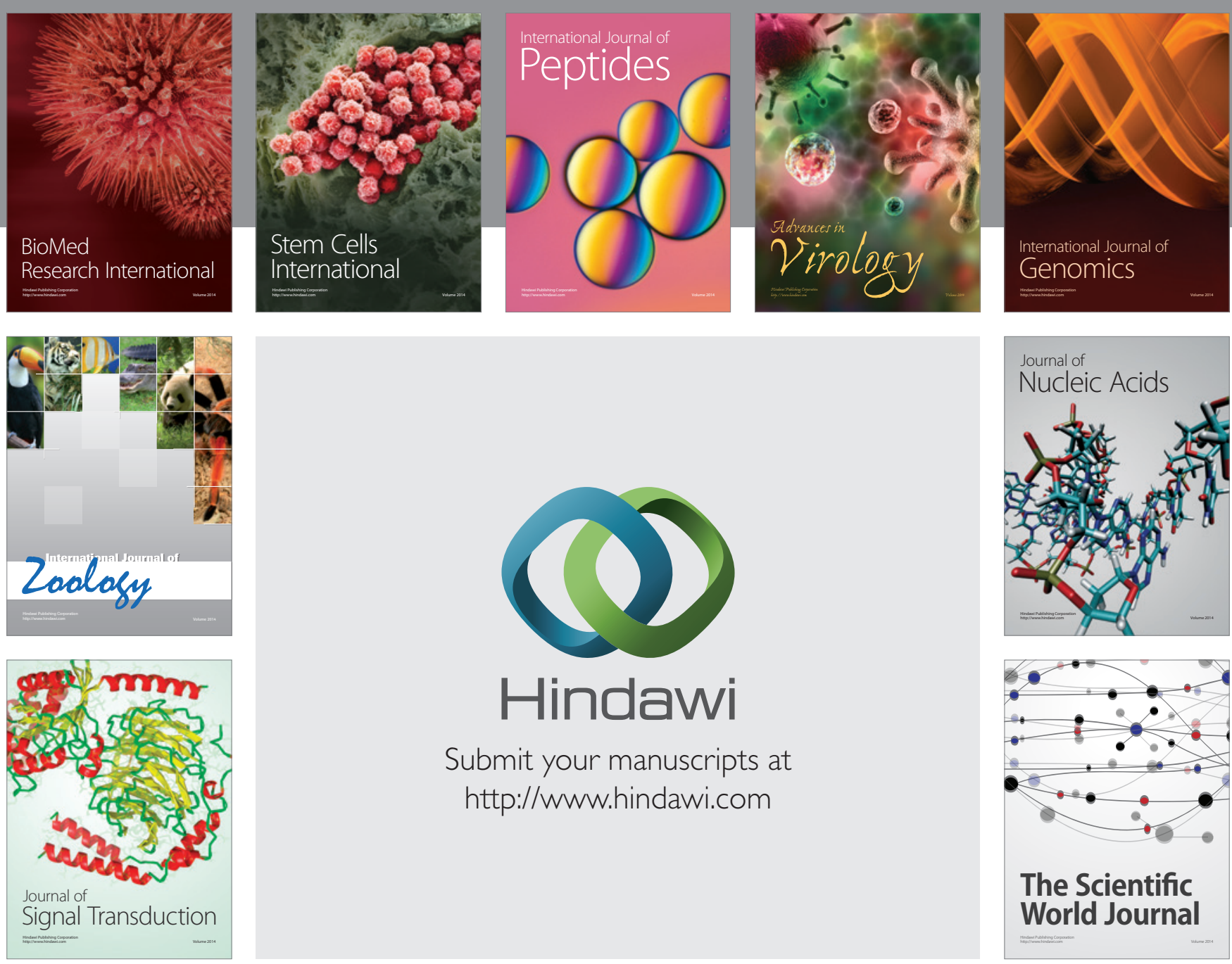

Submit your manuscripts at

http://www.hindawi.com
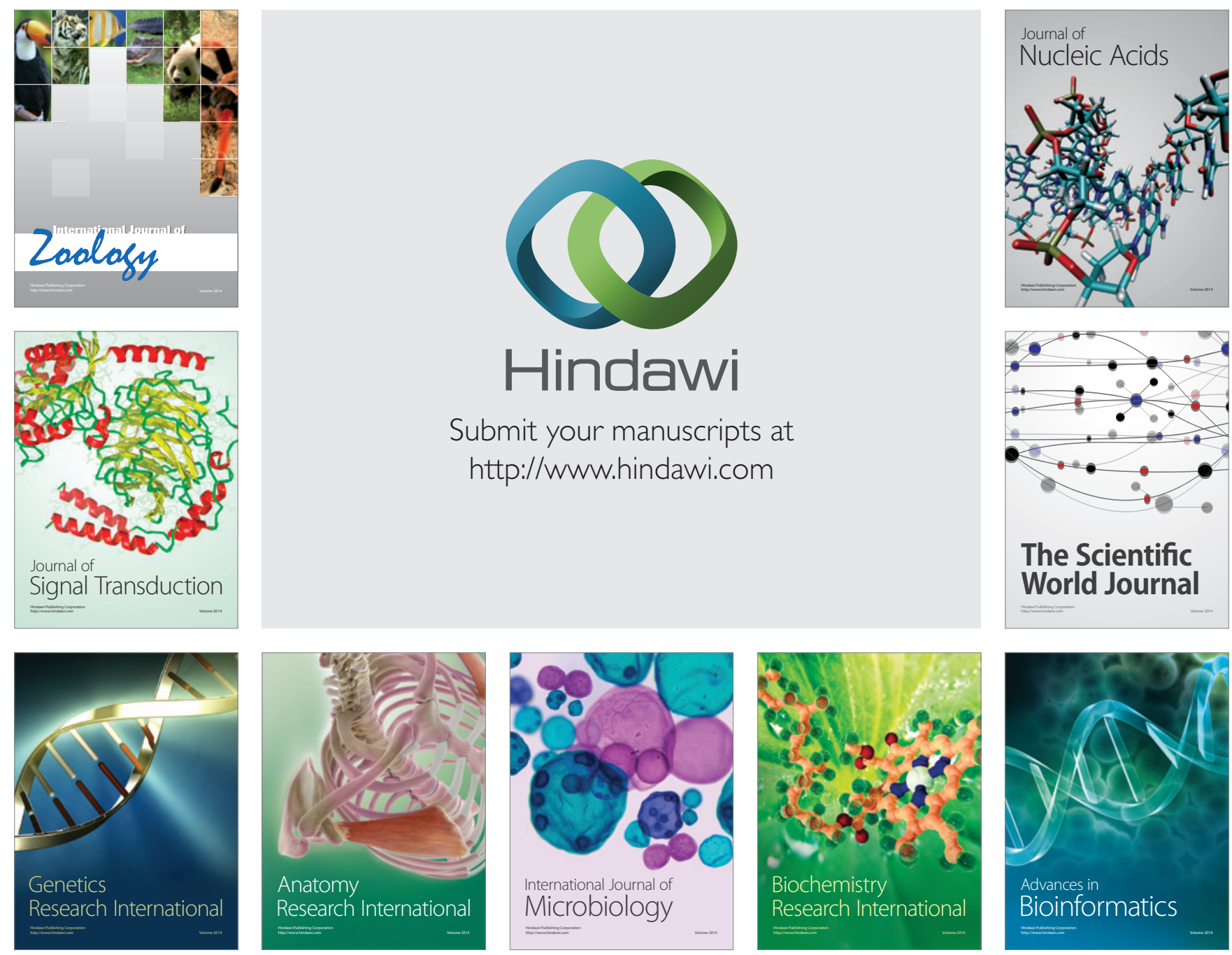

The Scientific World Journal
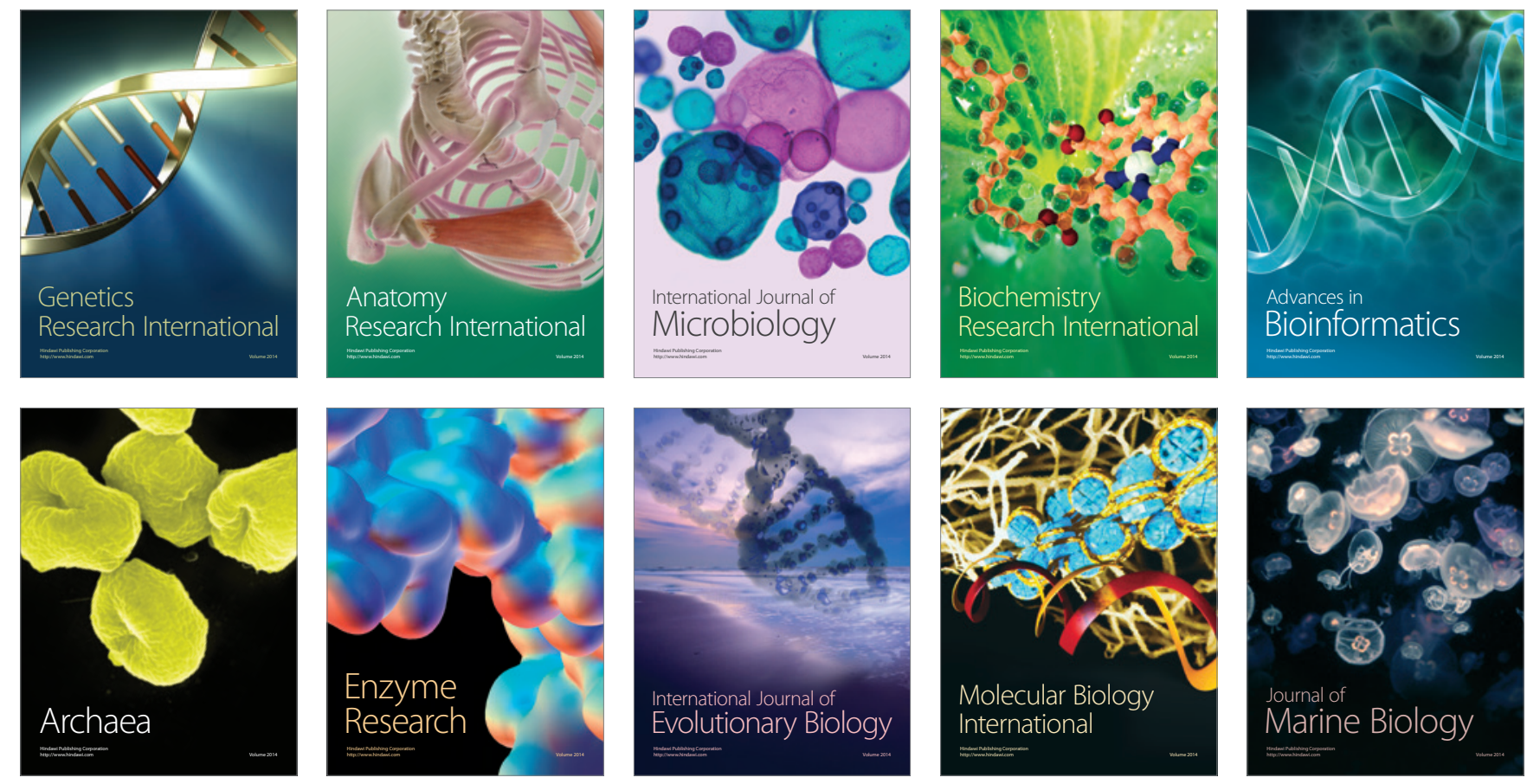